\title{
Influence of Light Intensity on Tobacco Responses to Drought Stress
}

Brwa Mohammad Ali Rasool

Agricultural Project Management Department

Halabja Technical College of Applied Science

Sulaimani Polytechnic University

Sulaimani, Iraq

brwa.rasool@spu.edu.iq

\begin{tabular}{l} 
Article Info \\
\hline Volume 6 - Issue 2- \\
December 2021 \\
DOI: \\
10.24017/science.2021.2.2 \\
Article history: \\
Received 1/2/2021 \\
Accepted 22/9/2021 \\
\hline
\end{tabular}

Keywords:

High light stress, drought stress, light memory, crosstolerance, redox regulation

\begin{abstract}
The influence of high irradiance, drought stress and their cross-talk interaction were explored in tobacco plants (Nicotiana tobaccum). Plants grown under low light $(250$

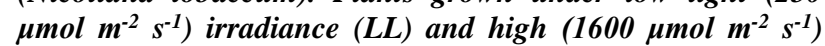
irradiance $(H L)$ then exposed to water deficient condition for 7 or 14 days. The detached leaves of HL-treated plants showed less water loss compared to LL plants. The HL-treated and 7 days drought-stressed plants had higher fresh and dry weights, as well as water content than the LL and droughtstressed leaves. The survival rate in 21 days drought-stressed plants after 3 days of re-watering was $50 \%$ in HL-grown and $0 \%$ in LL-grown plants.

A transcriptome profiling analysis of the tobacco responses to light intensity highlights the increased abundance of a large group of drought-related transcripts including DROUGHTRESPONSIVE ELEMENT BINDING FACTORS (DREBS), C-REPEAT/DROUGHT-RESPONSIVE BINDING FACTOR 1 (CBF1), GLYCINE-RICH RNA BINDING PROTEINS (GRPs), WRKY33 and MYCs transcription factors, as well as zeaxanthin epoxidase, which play as a regulator of plant responses to water deficient condition.

These findings identify light-dependent changes in the cell redox state that limit water loss and enhance plant responses to drought stress.
\end{abstract}

Copyright $(0) 2021$ Kurdistan Journal of Applied Research. All rights reserved. 


\section{INTRODUCTION}

Abiotic stresses are physical or chemical environmental factors posing a severe threat to crop yield loss. These include; low or high light intensity or temperature and water deficient condition $[1,2]$ Although light and water are key components of photosynthesis, excess light and water deficient can cause photooxidation and photoinhibition of chlorophyll via generation of reactive oxygen species (ROS). As a result, the efficiency of photosynthesis is reduced $[3,4]$.

Drought is a major environmental limiting factor and unpredictable constraint that negatively influence photosynthesis and plant production [5, 6]. Drought can interrupt various plant activities including the carbon assimilation rate, increase oxidative damage, decrease turgor and changes in leaf gas exchange. As a result, yield is severely reduced $[6,7,8]$.

Routinely plants expose to combined abiotic stresses [9, 10]. For example, under water deficient condition plants may expose to high light intensity or high temperature at the same time [10].

Plants experienced one type of stress can be tolerant to another type of stresses. This is known as cross-tolerance to the different abiotic stresses [11, 12].

The phenomenon of cross-tolerance is happening as a result of interactive activation of resistance pathways that induce plant tolerance to different types of stresses [13]. Such activations include cell signalling pathways, regulation in hormonal production and signalling, synthesis of secondary metabolites, as well as increasing in antioxidant and detoxification activity $[14,15,16]$.

Cross-tolerance enhances ROS production, which are messengers of stress signals and regulate plant defence responses to various stresses [17]. The photosynthetic electron transport chain makes chloroplast one of the main sites of ROS synthesis [18, 19]. Accumulated ROS in chloroplast enhance stomatal closure via increasing ROS concentration in the guard cells. As a result, transpiration is reduced and leaf water content is increased leading to improved drought resistance $[19,20]$. The generated ROS in chloroplast transform signal of stresses to the nucleus which activate defense genes and modify plant responses to different stresses [21].

Plants treated with HL were found to have increased expression of ROS scavenging related genes, as well as synthesis and signaling of Jasmonic acid (JA), abscisic acid (ABA), salicylic acid (SA) and auxin $[22,23]$.

Recent studies showed that plants pre-treated with high light (HL) retain a "memory" of the HL stress that persists when plants are returned to low light (LL) conditions. The activated signaling pathways by HL memory can enhance abiotic and biotic plant defence responses [16].

This study will assess the role of pre-treatment with HL on responses of tobacco plants to water deficient condition. In addition, the light-dependent changes in leaf transcriptome were determined.

\section{METHODS AND MATERIALS}

\subsection{Seeds and the conditions of plant growth}

The Terracult GmbH compost [pH (5-6), EC $<1 \mathrm{mS} / \mathrm{cm}$, Nitrogen $110 \mathrm{mg} / \mathrm{l}$, Phosphate 130 $\mathrm{mg} / \mathrm{l}$, Potassium $140 \mathrm{mg} / \mathrm{l}$ ) was used to grow wild type tobacco (Nicotiana tabacum L.) seeds in the controlled environment chambers. The photoperiod was $8 \mathrm{~h}$ under $\left(250 \mu \mathrm{mol} \mathrm{m} \mathrm{m}^{-2} \mathrm{~s}^{-1}\right)$ of light irradiance at $20^{\circ} \mathrm{C}$ and $60 \%$ of relative humidity [24].

\subsection{High light $(\mathrm{HL})$ treatments}

Light emitting diode (LED) lights were used for both LL and HL treatments. The LED lights were manufactured in the United Kingdom by a PhytoLux LED grow light technology. In low light (LL) growth condition tobacco plants was exposed to $\left(250 \mu \mathrm{mol} \mathrm{m}^{-2} \mathrm{~s}^{-1}\right)$ for 4 weeks. In high light (HL) growth condition tobacco plants had been exposed for 2 weeks to $(250 \mu \mathrm{mol}$ $\left.\mathrm{m}^{-2} \mathrm{~s}^{-1}\right)$ then treated with $\left(1600 \mu \mathrm{mol} \mathrm{m} \mathrm{m}^{-2} \mathrm{~s}^{-1}\right)$ for one week and returned to $\left(250 \mu \mathrm{mol} \mathrm{m}^{-2} \mathrm{~s}^{-1}\right)$ for another week [24]. 


\subsection{Drought treatments}

The LL and HL experienced tobacco plants at week four were used to study responses to drought stress. Before withholding the water, all plants were well irrigated with an equal amount of water. Half of LL and HL grown plants were exposed to withholding the water supply for the period of 7 or 14 days. The second half was maintained under the condition of well-watered.

For recovery test, some plants were maintained for 21 days under drought condition then to recover drought conditions and evaluate the survival rates the plants were re-watered for 3 days.

2.4 Measurement of Water Loss in Detached Leaves (\%)

The LL and HL experienced tobacco leaves at 4-week-old were used for the measurement of water loss. The detached leaves were weighed directly after harvest and periodically every 15 minutes using electronic balance. The water loss percentage was found by dividing the decreased fresh weight by the previous fresh weight, multiply by 100 . Detached leaves were incubated under stable environmental conditions at room temperature at the time of measurements. The measurement was performed three times, using different plants and three plant replicates were used at each time [25].

2.5 Assessment of biomass (Fresh and dry weights) of shoot and root ( $g F W)$ and ( $g D W)$

The LL and HL experienced tobacco shoot and root fresh weights $(\mathrm{FW})$ were measured using electronic balance. For dry weight (DW), the shoot and root were dried at $70^{\circ} \mathrm{C}$ for 3 days in an oven and the dried tissues were weighed. 10 plant replicates were used per each measurement [25].

2.6 Root length $(\mathrm{cm})$

The length of roots was determined using measuring tape. This measurement was taken from

10 plants per treatment.

2.7 Assessment of leaf relative water content $(R W C)(\%)$

Mature leaves from LL and HL tobacco plants were harvested before drought and after 7 or 14 days of drought treatment. Immediately the collected leaves were weighed to record the FW. Then the distilled water was used to saturate the leaves with water for $24 \mathrm{~h}$, then the excess water was removed with tissue and leaves were weighed to measure leaves turgid weight (TW). The DW was obtained by drying the leaves at $70^{\circ} \mathrm{C}$ for 3 days and then weighed. The measurement was repeated three times with three plant replicates. The RCW was calculated according to [25] as:

$$
R W C=(F W-D W) /(T W-D W) \times 100
$$

\subsection{Assessment of relative water content in the soil (\%)}

The soil DW was subtracted from the weight of moist soil and divided by the soil DW in order to measure the soil relative water contents. The soil was dried at $90^{\circ} \mathrm{C}$ for 3 days using an oven to obtain the soil DW [25]. This measurement was taken from 3 plants per treatment.

\subsection{Survival rate (\%)}

The survival rate of 21 days drought-stressed plants was determined 3 days after re-watering to recover drought conditions. The survival rate was evaluated in 10 plants per treatment.

\subsection{Pigment analysis ( $\mu g \mathrm{~g} F W^{-1}$ )}

Mature leaves from LL and HL tobacco plants were harvested at week four to estimate chlorophyll and carotenoids contents of the leaves. Liquid nitrogen was used to ground 100 $\mathrm{mg}$ of the leaf samples and the ground sample was homogenised in $10 \mathrm{ml} 95 \%$ ice-cold ethanol. The extracts were separated using centrifuge at $(14000 \mathrm{~g})$ at $\left(4^{\circ} \mathrm{C}\right)$ for $10 \mathrm{~min}$. The photosynthetic pigments was estimated in the supernatant fractions by spectrophotometry according to the method of [26]. Pigments were estimated in three independent plants per each treatment.

2.11 Light response curves (LRCs) $\left(\mu \mathrm{mol} \mathrm{m} \mathrm{m}^{-2} \mathrm{~s}^{-1}\right)$

The LRCs for photosynthesis of LL and HL tobacco leaves were measured using Infrared Gas Analyser (LI-COR). During the measurement in the LI-COR leaf chamber, the $\mathrm{CO}_{2}$ concentration was $\left(400 \mu \mathrm{mol} \mathrm{mol}^{-1}\right)$ at $20^{\circ} \mathrm{C}$. The $\mathrm{CO}_{2}$ assimilations were measured at $(0,20$, 
$50,200,400,800$ and $1600 \mu \mathrm{mol} \mathrm{m}^{-2} \mathrm{~s}^{-1}$ ) photosynthetically active radiation (PAR) levels. At each PAR he leaves were acclimatized for $15 \mathrm{~min}$. This measurement was taken from 5 plants per treatment [27].

\section{$2.12 \mathrm{CO}_{2}$ response curves $\left(\mu \mathrm{mol} \mathrm{m}^{-2} \mathrm{~s}^{-1}\right)$}

The $\mathrm{CO}_{2}$ response curves for photosynthesis of $\mathrm{LL}$ and $\mathrm{HL}$ tobacco leaves were measured using Infrared Gas Analyser (LI-COR). During the measurement in the LI-COR leaf chamber the PAR was $\left(250 \mu \mathrm{mol} \mathrm{m} \mathrm{m}^{-2} \mathrm{~s}^{-1}\right)$ at $20^{\circ} \mathrm{C}$. The $\mathrm{CO}_{2}$ assimilations were taken at $(0,200,400$, 600, 800 and $\left.1000 \mu \mathrm{mol} \mathrm{mol}^{-1}\right) \mathrm{CO}_{2}$ concentrations. At each $\mathrm{CO}_{2}$ concentration the leaves were acclimatized for $15 \mathrm{~min}$ [27]. This measurement was taken from 5 plants per treatment.

\subsection{RNA Extraction and microarray analysis}

Microarray analysis was conducted to investigate the genes that different in abundance between LL and HL grown tobacco leaves. For each treatment three independent biological replicates were analysed. The total RNA was purified from leaf samples using Plant Mini Kit provided by Qiagen ${ }^{\circledR}$ RNeasy.

The microarray analysis was performed at James Hutton Institute, Dundee, UK, according to the protocol described in [24].

\subsection{Statistical analysis}

The statistical analysis was performed using randomized complete design (Two-way ANOVA-RCD). The mean was compared by Duncan's Multiple Range Test with a $P$-value of $<0.05$. The software IBM SPSS Statistics was used for the analysis. The mean of data \pm standard error of the mean (SEM) was represented.

\section{RESULTS}

\subsection{Shoot Phenotypes of LL and HL Tobacco Plants Well-Watered or Subjected to Water Deficient Conditions}

The tobacco plants under both LL and HL conditions had similar shoot phenotypes, a part of the pale yellow color of HL leaves (Figure 1a). However, plant treatment with withholding water for 7 or 14 days resulted in appearance of wilting symptoms (Figure 1a). The wilting symptoms were more sever in 14 days drought-stressed plants.

Seven days of HL treatment led to about $30 \%$ reduction in the leaves chlorophyll content relative to LL leaves (Figure 1b). In contrast, non-significant difference was observed in carotenoid content of the leaves under both light regimes (Figure 1b).

A
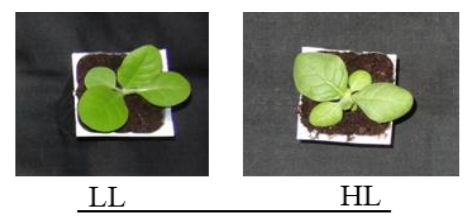

$\mathrm{HL}$

Before drought

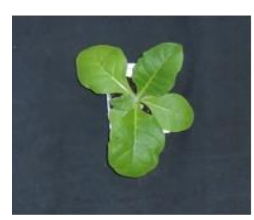

$\underline{\mathrm{LL}}$

Well-watered

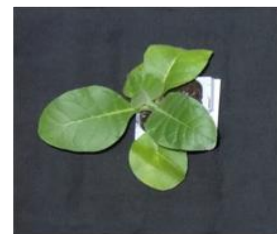

$\underline{\mathrm{LL}}$

Well-watered

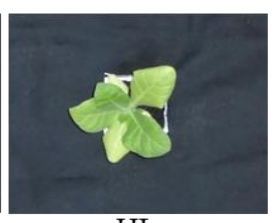

$\mathrm{HL}$

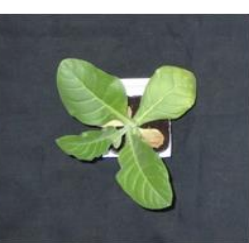

$\mathrm{HL}$

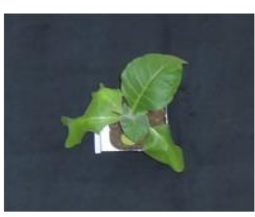

$\underline{\mathrm{LL}}$

7 days of drought

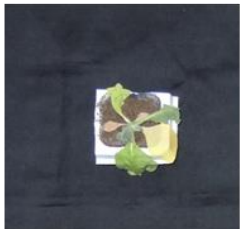

LL 14 days of drought 


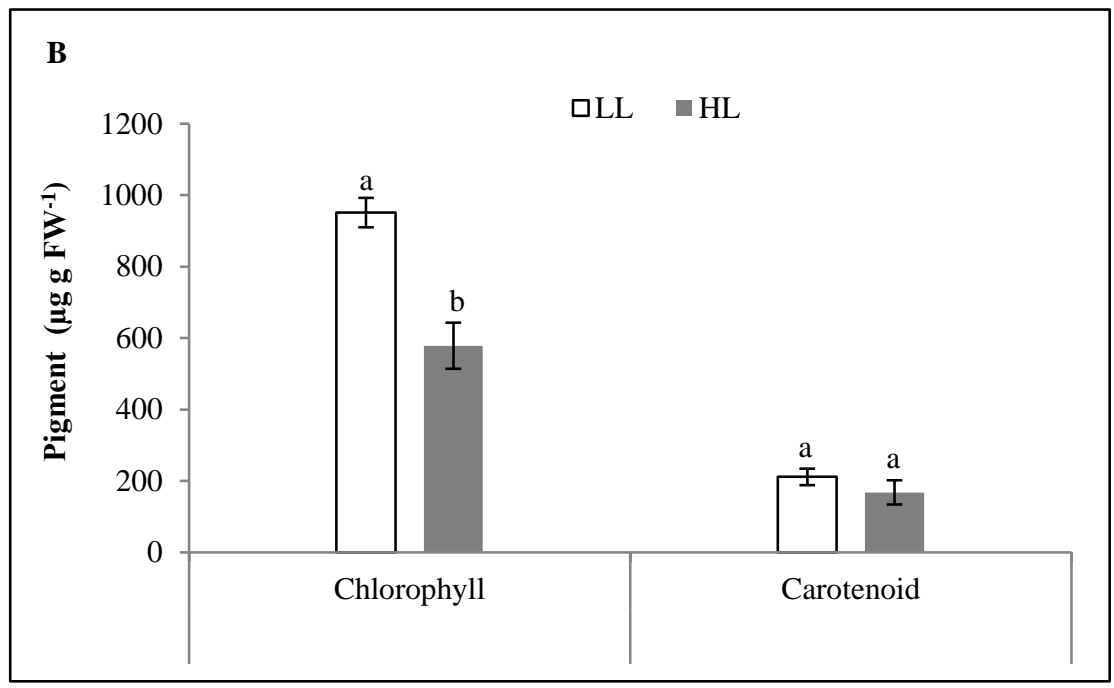

Figure 1: Shoot phenotype of LL and HL tobacco plants well-watered or subjected to drought. (A) Representative photographs. (B) Photosynthetic pigments in LL and HL tobacco leaves. Data are means of three replicates \pm SEM. The letters show statistical differences among the means.

Data of LRCs and $\mathrm{CO}_{2}$ response curves illustrated that the slope of $\mathrm{LRCs}$ and $\mathrm{CO}_{2}$ curves were slightly decreased due to HL pre-treatment (Figure 2a,b). The significant decrease in the slope of both curves was only recorded between $\left(200-400 \mu \mathrm{mol} \mathrm{m}^{-2} \mathrm{~s}^{-1}\right.$; (Figure 2a,b).

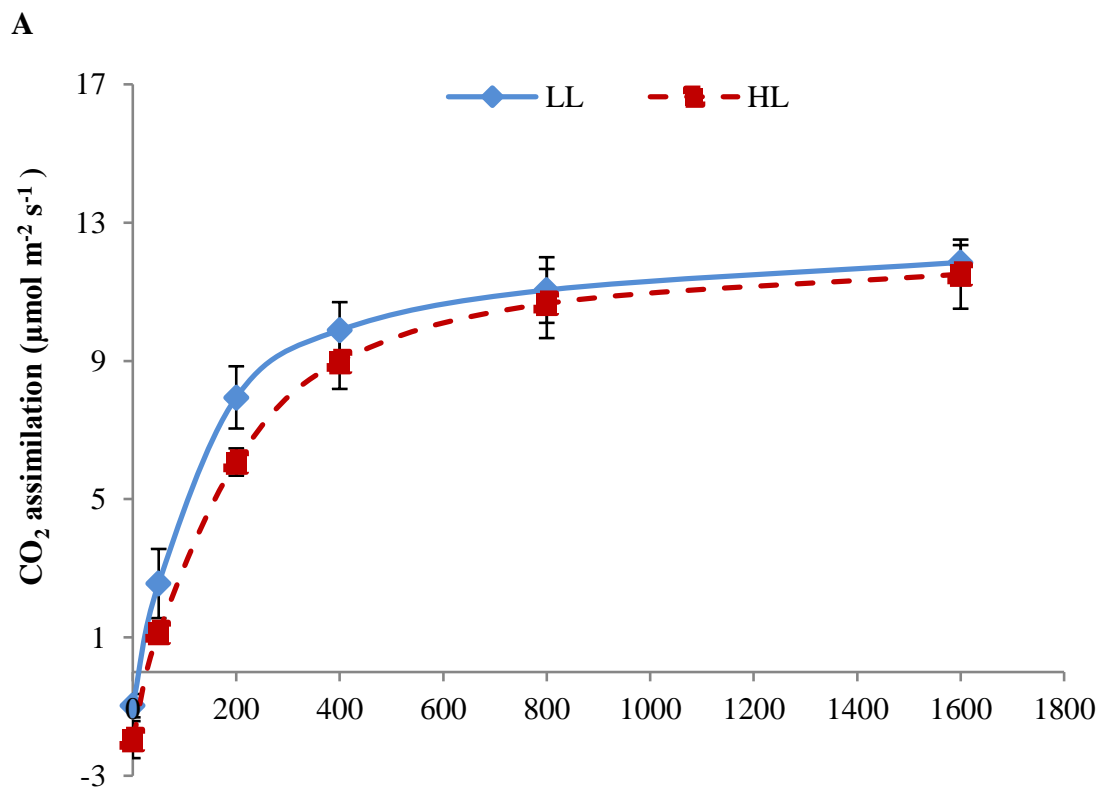

$\operatorname{PAR}\left(\mu \mathrm{mol} \mathrm{m} \mathbf{m}^{-2} \mathrm{~s}^{-1}\right)$ 


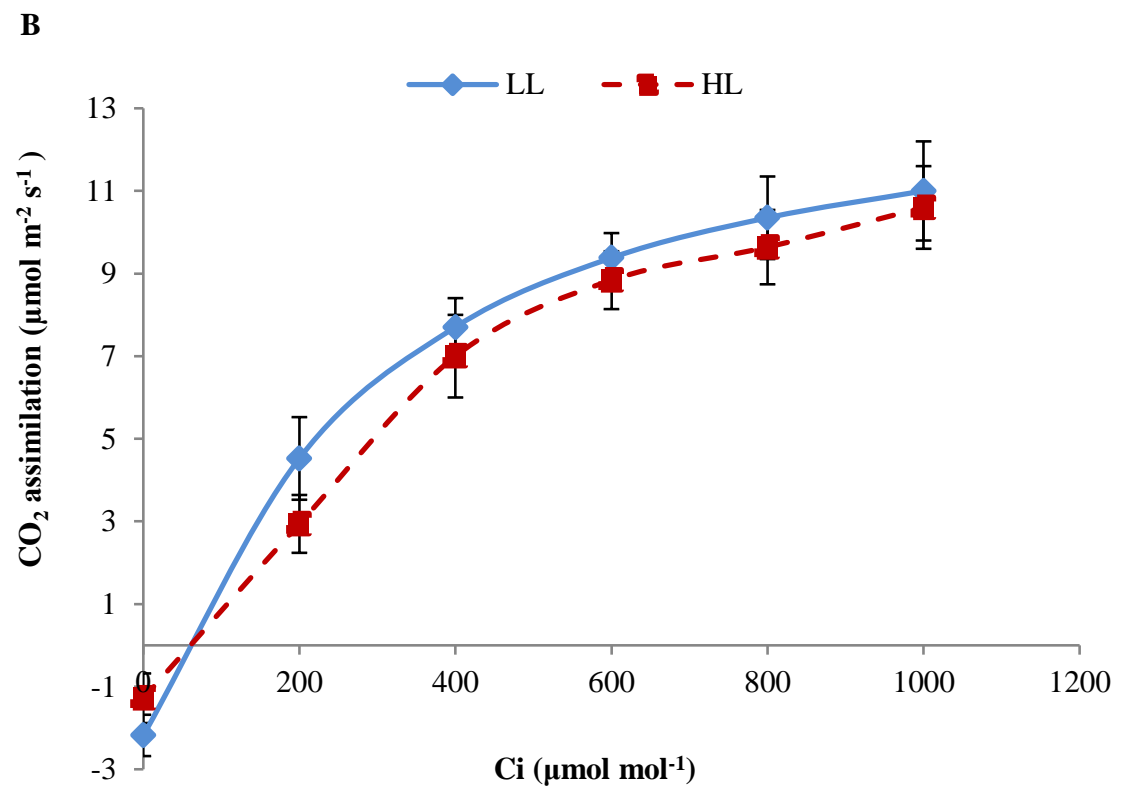

Figure 2: Light responsive curves (A) and $\mathrm{CO}_{2}$ responsive curves (B) for photosynthesis in $\mathrm{LL}$ and $\mathrm{HL}$ tobacco plants. Data are means of five replicates \pm SEM.

Before drought treatment, the LL-grown plants had significantly smaller biomass accumulation than the plants grown under HL growth conditions for one week (Figure 3a, b). HL-treated and 7 days drought-stressed plants had higher fresh and dry weights than the LLgrown plants (Figure 3a, b). Similarly, plants treated with HL and well-watered for 7 days had higher dry weight than the LL plants (Figure 3b). The fresh and dry weights in both LL and HL-grown plants were significantly decreased due to the progression of drought stress to 14 days (Figure 3a, b) relative to well-watered plants.

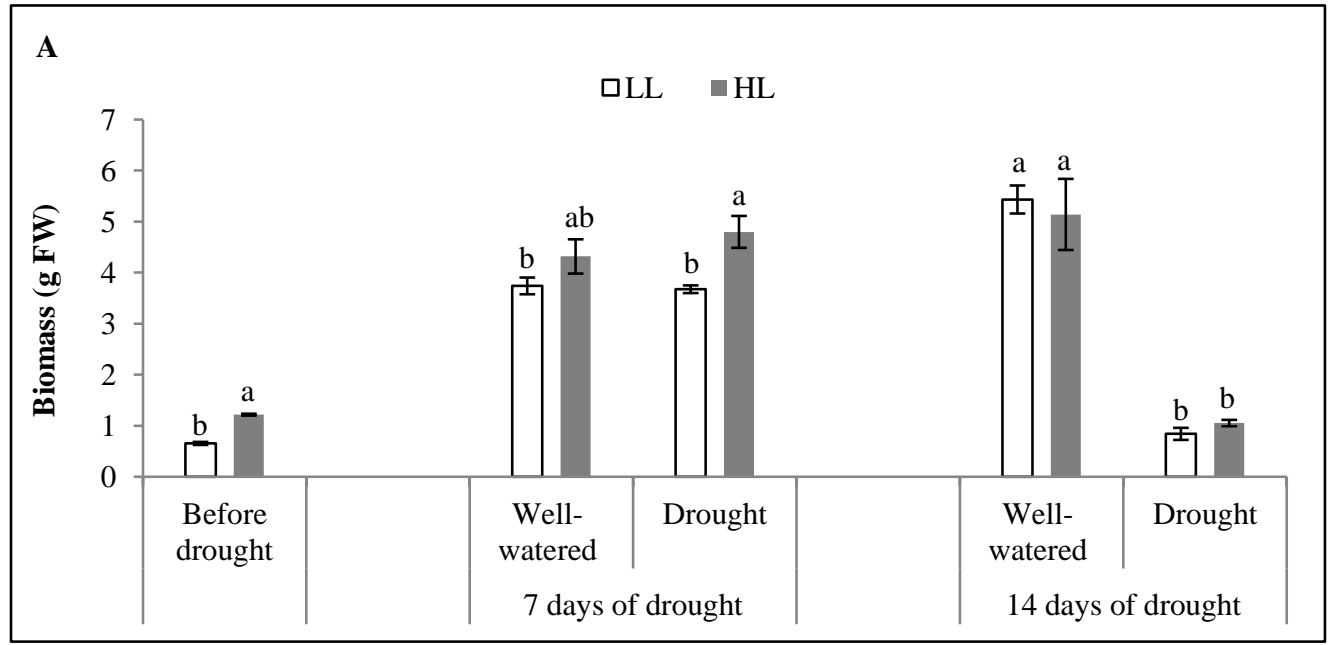




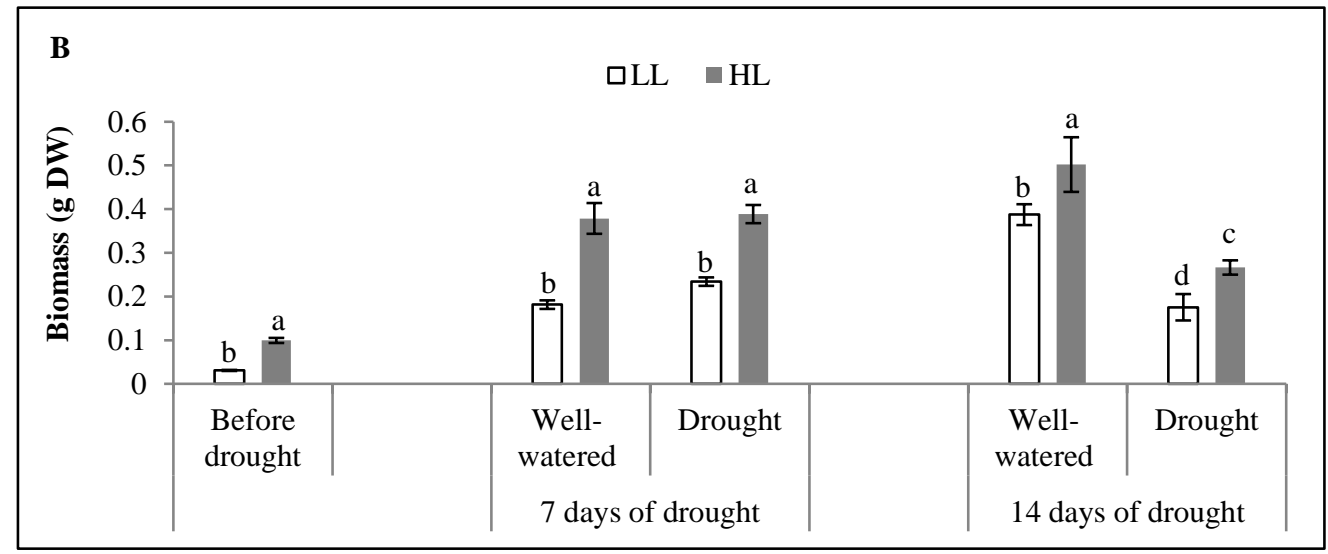

Figure 3: Biomass of LL and HL tobacco plants well-watered or subjected to drought. (A) Fresh weight. (B) Dry weight. Data are means of ten replicates \pm SEM. The letters show statistical differences among the means.

The root length (Figure $4 \mathrm{a}, \mathrm{b}$ ) and root biomass (Figure 5a, b) of HL treated plants were significantly increased compared to plants treated with LL under both water regimes.

A

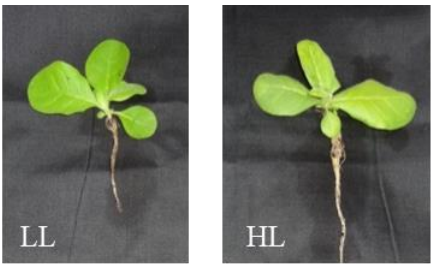

Before drought

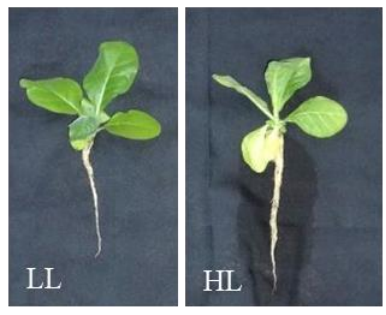

Well-watered

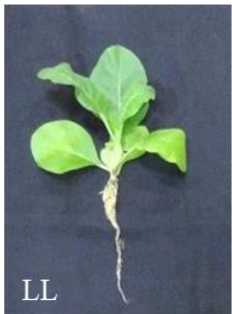

Well-watered

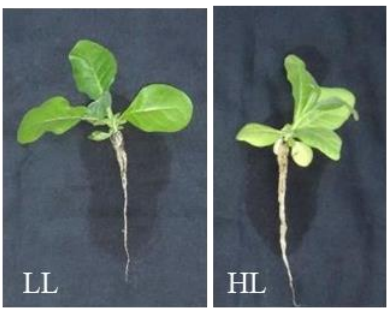

7 days of drought

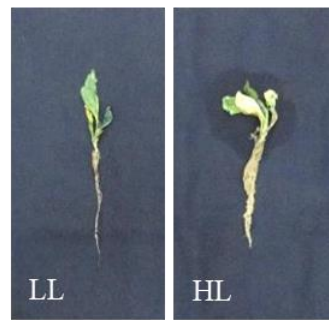

14 days of drought 


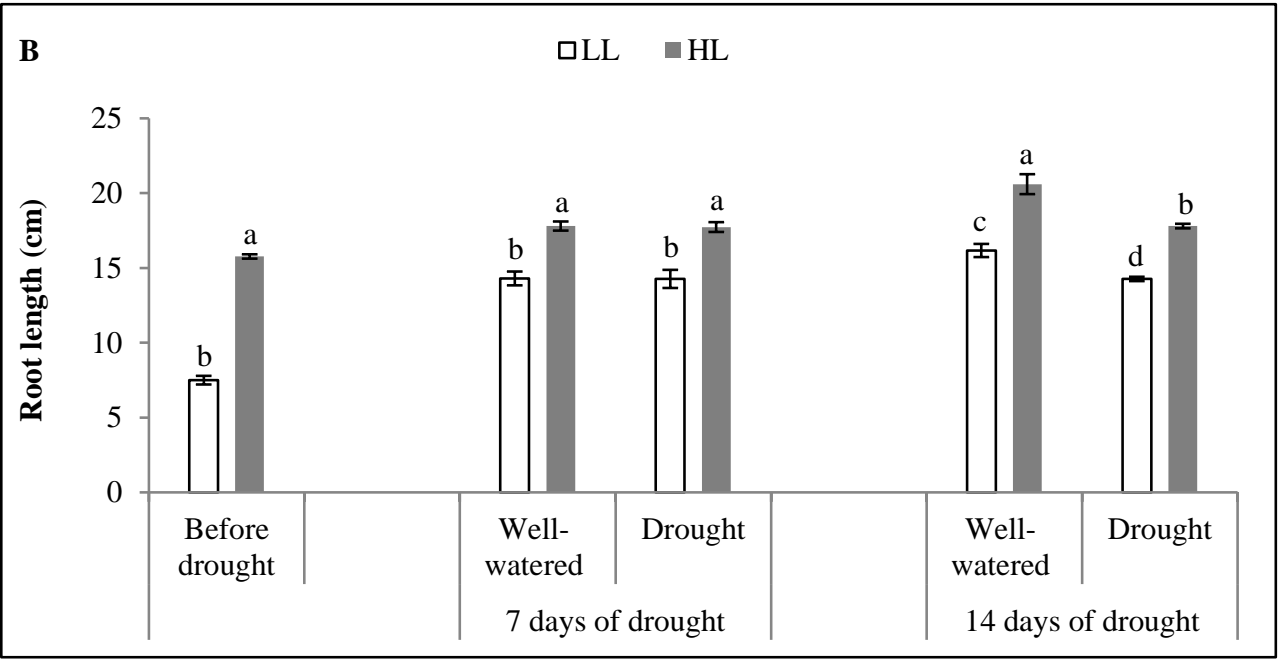

Figure 4: Representative photographs and root system of LL and HL tobacco plants well-watered or subjected to drought. (A) Representative photographs of root system. (B) Root length. Data are means of ten replicates \pm SEM. The letters show statistical differences among the means.
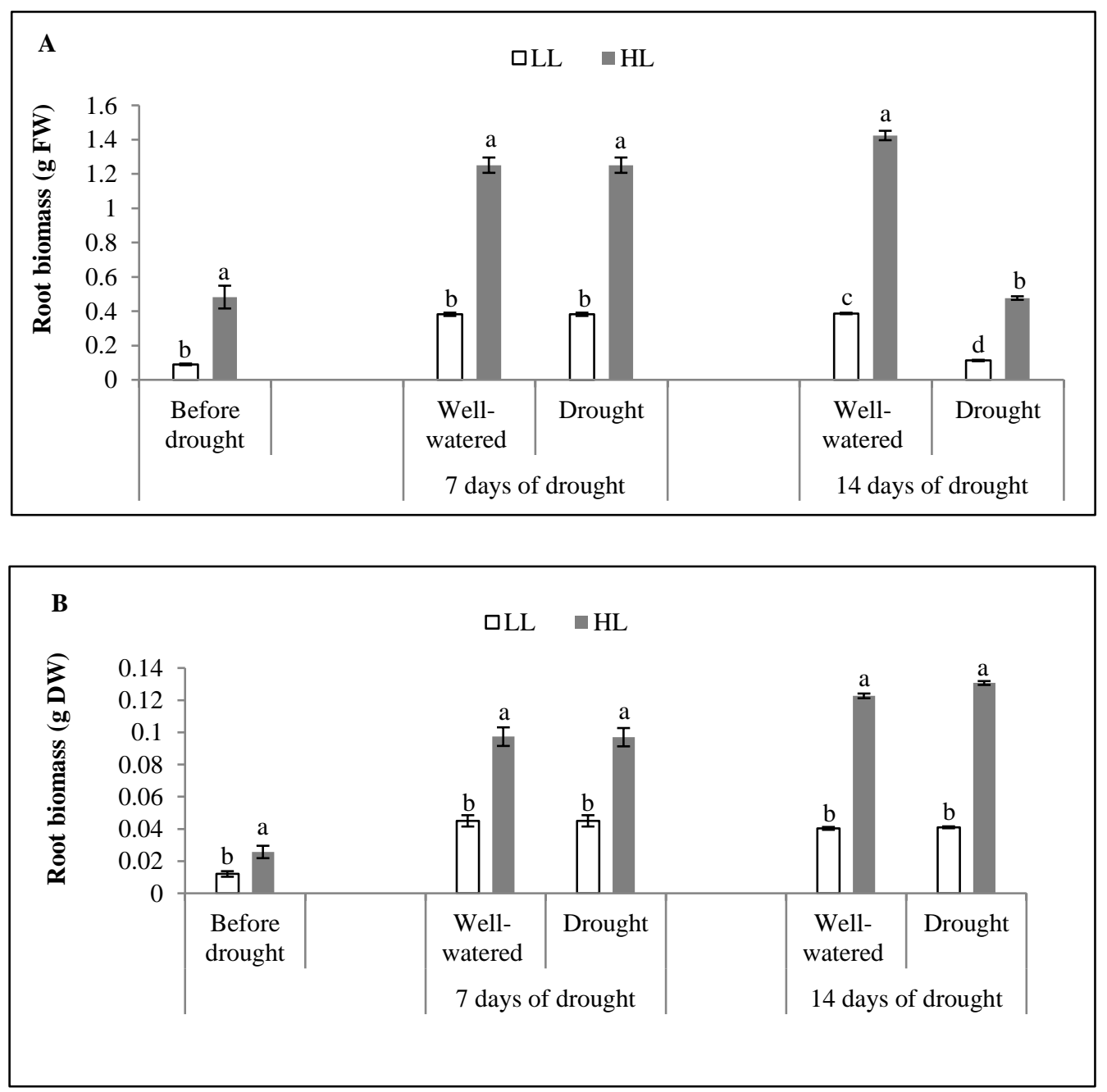
Figure 5: Root biomass of LL and HL tobacco plants well-watered or subjected to drought. (A) Root fresh weight. (B) Root dry weight. Data are means of ten replicates \pm SEM. The letters show statistical differences among the means.

\subsection{High Light Grown Tobacco Plants Showed less water loss and higher survival rate}

The detached leaves of HL-treated plants showed less water loss relative to LL leaves (Figure $6 a)$. With the exception of the HL-grown and 7 days drought-stressed plants, the leaves had non-significant differences in water content under all conditions (Figure 6b). The leaves of HL-grown and 7 days drought-stressed plants had higher leaf water content relative to LL and 7 days drought-stressed plants (Figure 6b). Water withholding for 7 and 14 days significantly decreased the soil water content compared with well-watered growth conditions (Figure 6c). This reduction in relative soil water content was more marked under 14 days drought conditions (Figure 6c).

Moreover, the soil of HL-grown and 7 days drought-treated plants had lower water content than the soil of LL-grown and 7 days drought-treated plants (Figure 6c).

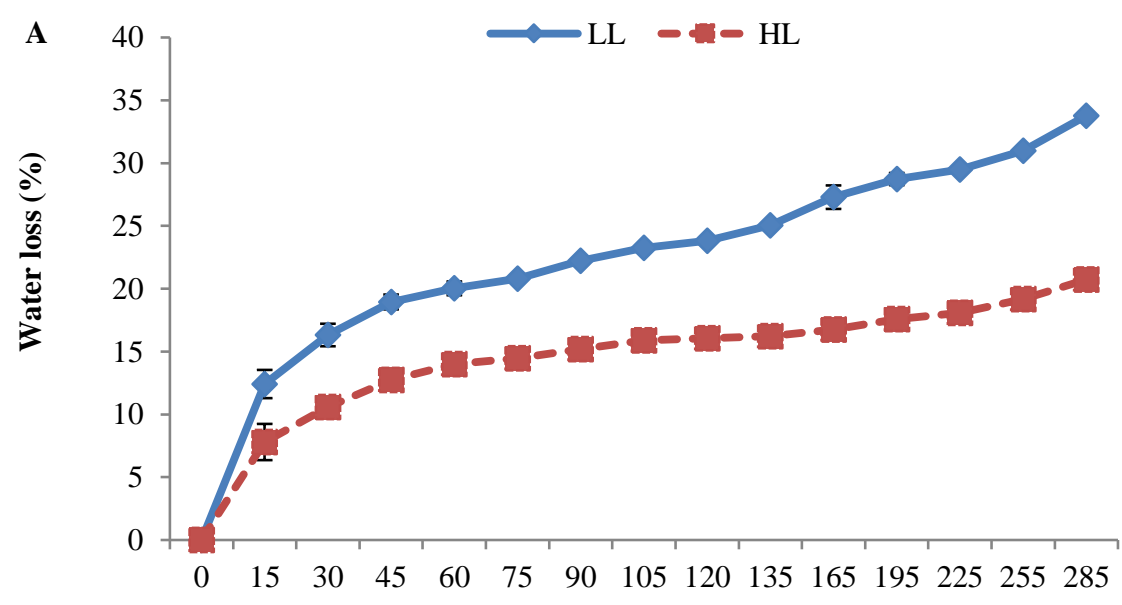

Time (min)

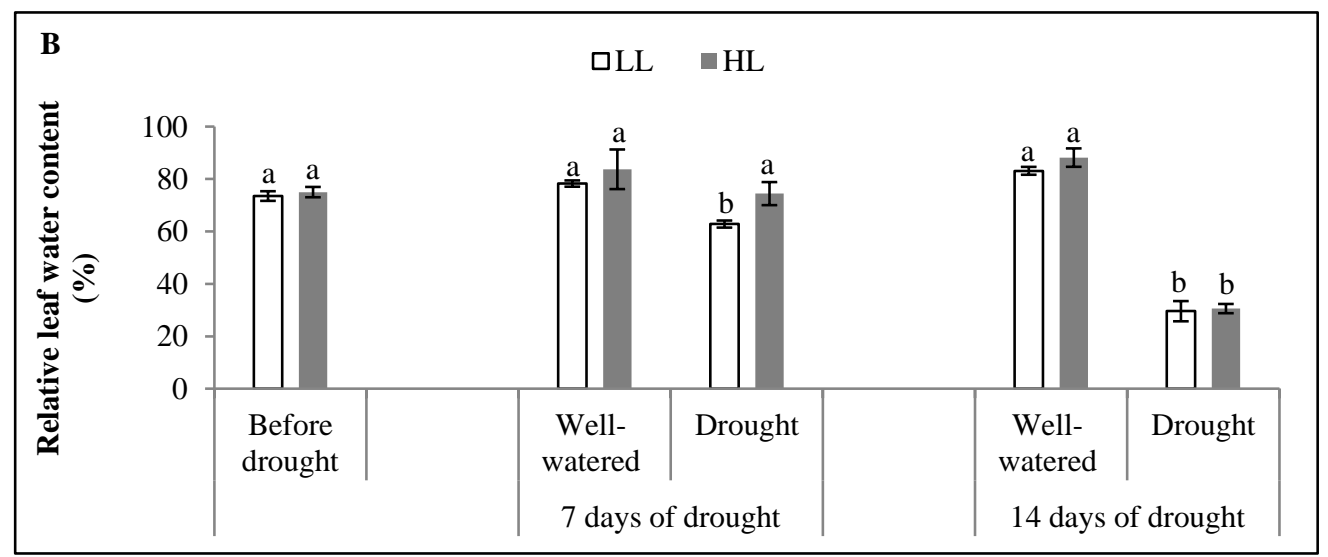




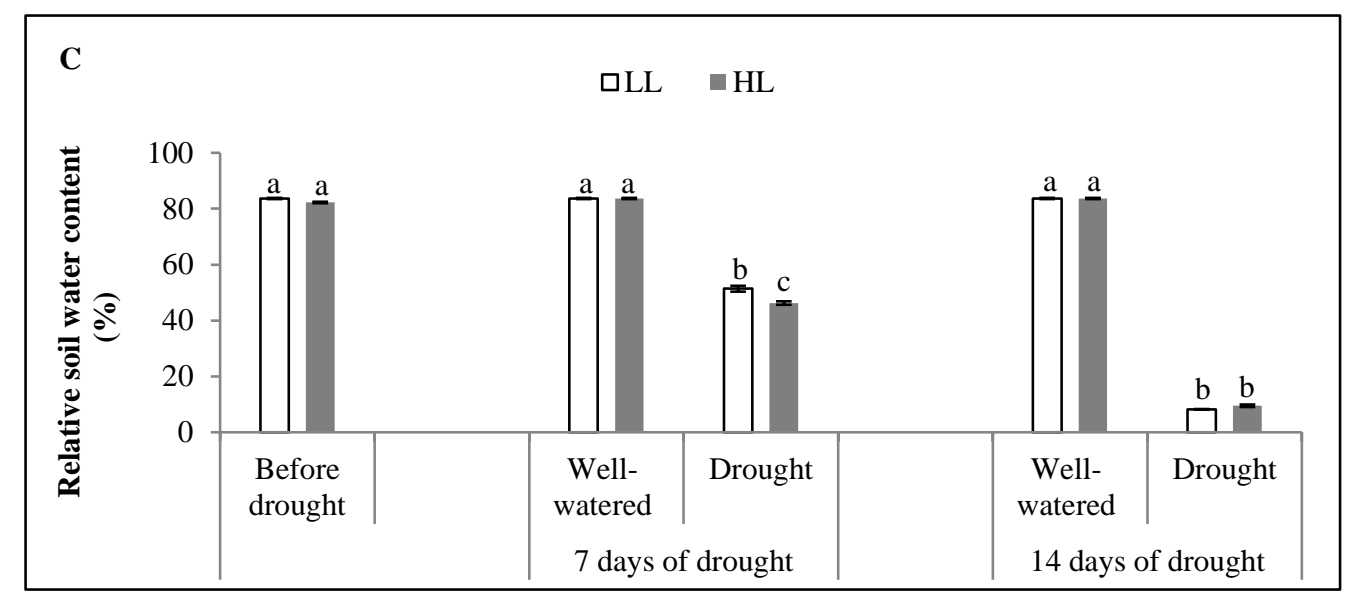

Figure 6: Water loss (A), water content in the leaves (B) and the soil (C) of LL and HL tobacco plants well-watered or subjected to drought. (A) Data are means of three replicates \pm SEM. The letters show statistical differences among the means.

In order to evaluate the survival rate in drought stressed-plants, some plants were maintained for 21 days under drought condition then to recover drought conditions the plants were rewatered for 3 days. About 50\% of HL-grown plants survived, whereas none of LL plants survived after re-watering (Figure $7 \mathrm{a}, \mathrm{b}$ ).

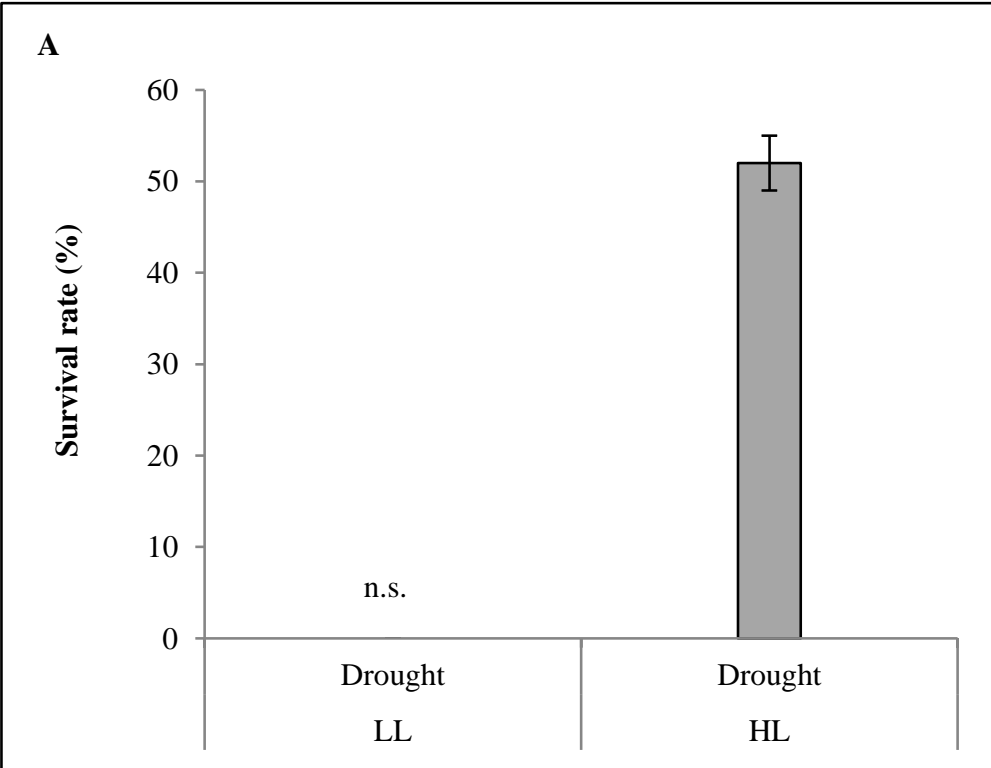



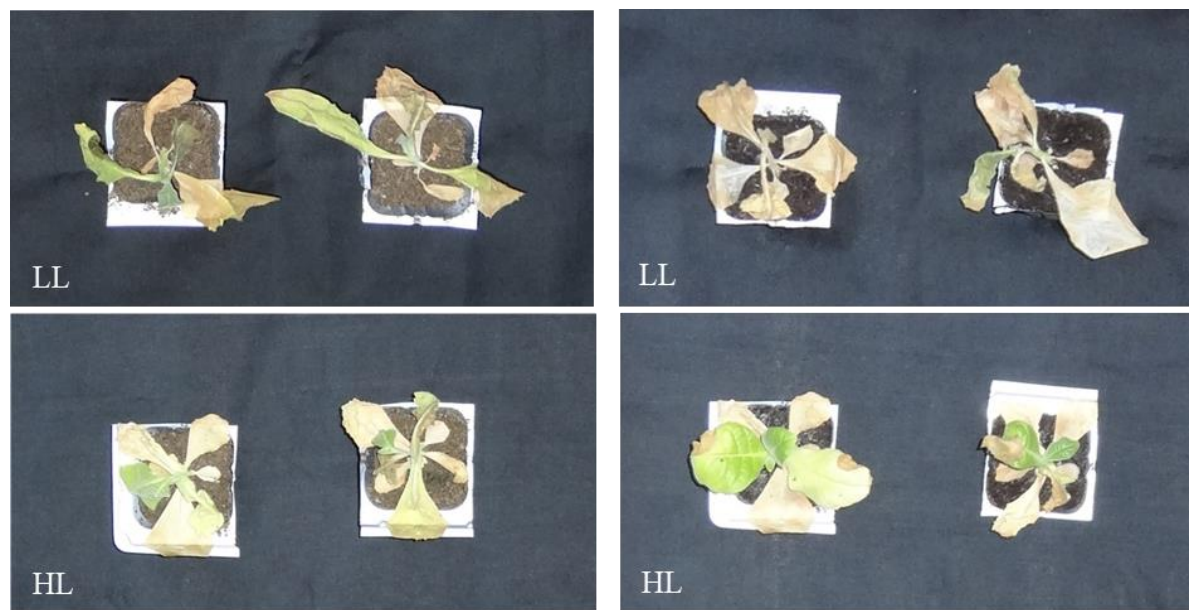

Drought for 21 days

Re-watered for 3 days

Figure 7: Morphological characterizations of survived LL and HL tobacco plants subjected to water deficient conditions for 21 days then re-watered for 3 days. (A) Survival rate of tobacco plants (B) Representative photographs of survived plants. Data are means of ten replicates \pm SEM. N.s., not survived.

\subsection{The HL treatment distinctly altered the Profile of Transcripts in Tobacco Leaves}

An analysis of the leaf transcript profiles was performed to determine the light-dependent modifications in transcriptome of LL and HL grown leaves.

Analysis of variance indicated that HL changed the abundance of 2502 transcripts of which 1729 were more and 773 were less abundant relative to LL grown leaves (Figure 8). 

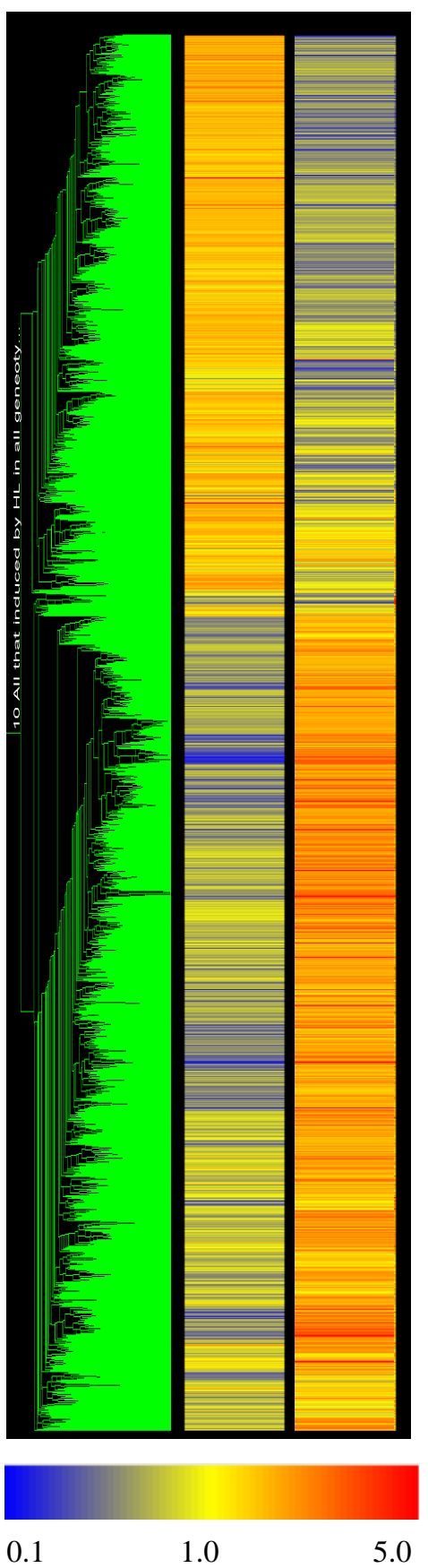

Figure 8: Hierarchical clustering of differentially expressed genes in the leaves of LL and HL tobacco plants. The genes that differentially expressed under HL relative to LL were tested by using two-way ANOVA $(P<0.05)$. The GeneSpring was used for the analysis of variance with (Benjamini-Hochberg) as multiple testing corrections. Gene Ontology (GO) was used in order to classify the genes into the functional groups in the website of agriGO (http://bioinfo.cau.edu.cn/agriGO/). 
Functional classification analysis of the transcripts showed that the metabolic related transcripts were more abundant in HL treated leaves (Figure 9). Transcripts related to stimulus responses, stress responses, chloroplast, DNA binding, transcription factor and metabolism were significantly differentially abundant under growth irradiances (Figure 9).

The transcript groups associated with stimulus responses, stress responses, chloroplast, DNA binding and transcription factor were more abundant in the leaves pre-treated with HL for one week (Figure 9). Transcripts encoding photosynthesis, signal transduction, transporter activity and cell wall were other functional groups that their abundance increased in response to HL treatment (Figure 9).

Conversely, the functional analysis showed a de-repression in the abundant of transcripts related to stimulus responses, metabolism, DNA binding, transcription factor and transporter activity in HL leaves compared to LL (Figure 9).

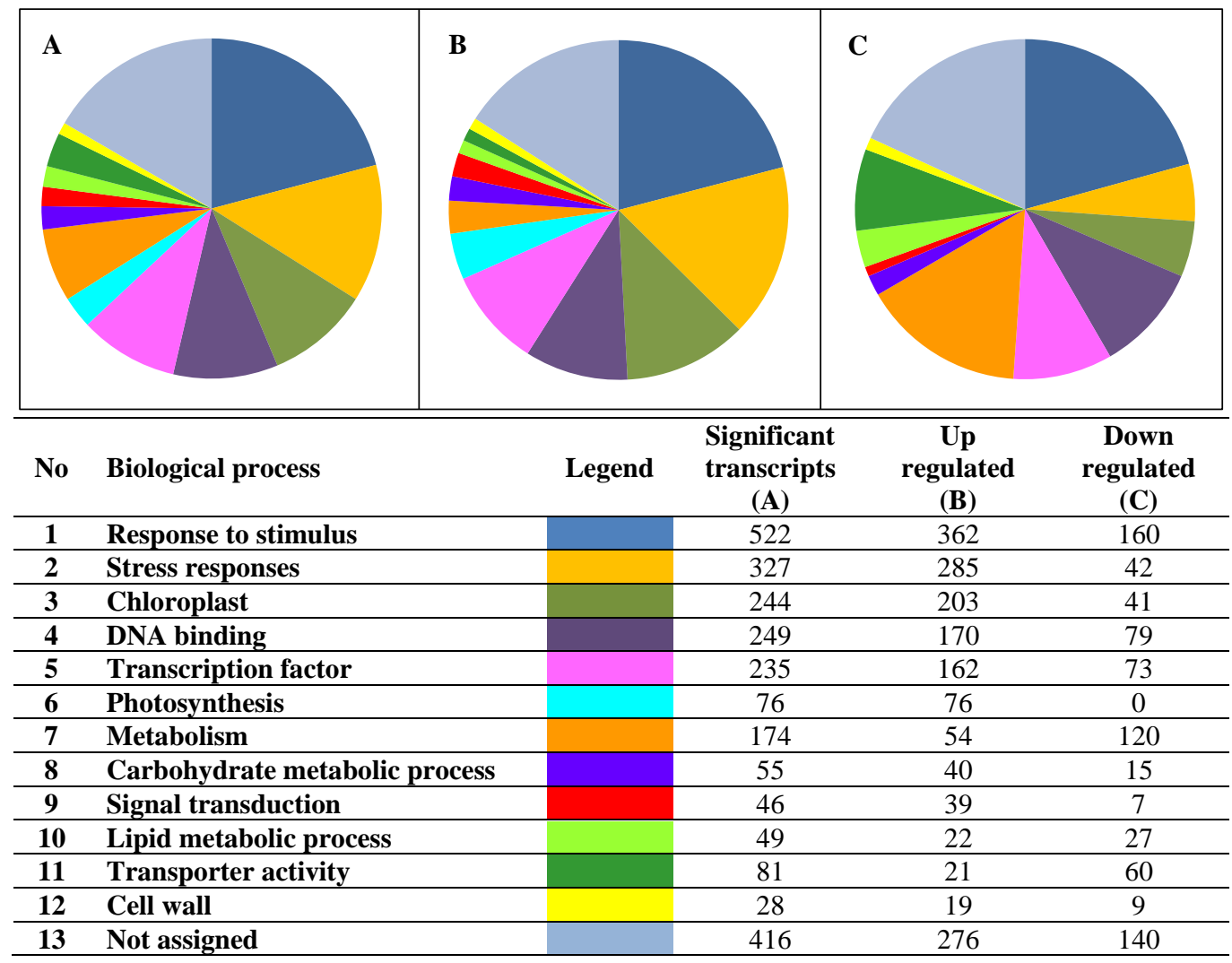

Figure 9: Functional classifications of differentially abundant transcripts in response to HL relative to LL. (A) Venn diagram of the total numbers of differentially abundant transcripts. (B) Venn diagram of more abundant transcripts. (C) Venn diagram of less abundant transcripts. The table lists show the transcripts that differentially abundant and the size of each functional group (number of genes). The genes that differentially expressed under HL relative to LL were tested by using two-way ANOVA ( $P<$ 0.05 ). The GeneSpring was used for the analysis of variance with (Benjamini-Hochberg) as multiple testing corrections. Gene Ontology (GO) was used in order to classify the genes into the functional groups in website of agriGO (http://bioinfo.cau.edu.cn/agriGO/). 
Amongst the stress responses transcripts that represented in more abundant under HL conditions, 27 transcripts were related to water stress condition (Table 1).

For example, transcripts encoding DROUGHT-RESPONSIVE ELEMENT BINDING FACTORS (DREB and DREB2A) were induced due to HL treatment (Table 1).

The DREBs involve in the activation of drought associated genes [28, 29]. Moreover, the leaves treated with HL accumulated transcripts encoding C-REPEAT/DROUGHTRESPONSIVE BINDING FACTOR 1 (CBF1), which encodes the DREB1 subfamily and play pivotal role in plant tolerance to water deficient condition (Table 1) [30,31].

The level of transcripts encoding the GLYCINE-RICH RNA BINDING PROTEIN (GRPs) was induced by HL treatment (Table 1). The GRP1 and GRP2 induce drought tolerance through enhancing stomatal closure and reducing water loss [32, 33]. The abundance of transcripts encoding WRKY33 and MYCs transcription factors were induced due to HL treatment (Table 1). The WRKY33 and MYCs play crucial role in the induction of drought defence responses via JA and ABA signalling [34, 35, 36]. The HL-treated leaves accumulated transcripts encoding zeaxanthin epoxidase (ZEP; Table 1). The ZEP is the catalyzing enzyme of xanthophyll cycle and ABA biosynthesis. Both processes are required for plant acclimations to high irradiance stress and water deficient conditions [37].

Detoxification enzyme-encoding transcripts such as glutathione S-transferases (GSTs) were induced due to HL pre-treatment (Table 1). GSTs are detoxification enzyme against ROS and strengthen the ability of ROS scavengers in ascorbate-glutathione cycle and regulate various stress responses [38, 39].

Table 1: Drought responsive-related transcripts that present in higher abundance in HL grown tobacco leaves relative to LL. The genes that differentially expressed under HL relative to LL were characterized by using two-way ANOVA $(P<0.05)$. The GeneSpring was used for the analysis of variance with (Benjamini-Hochberg) as multiple testing corrections. Gene Ontology (GO) was used in order to classify the genes into the functional groups in website of agriGO (http://bioinfo.cau.edu.cn/agriGO/).

\begin{tabular}{lll}
\hline Accession & Fold change & Gene Description \\
\hline EB440199 & 4.96 & Drought-Responsive Element Binding factor (DREB) \\
\hline FG167555 & 4.94 & C-Repeat/Drought-Responsive Binding factor 1 ( CBF1) \\
\hline FG139571 & 3.36 & Glycine-Rich RNA binding protein 1 (GRP1) \\
\hline AB063573 & 3.18 & WRKY33 transcription factor \\
\hline AB022693 & 2.54 & Putative GEM-like protein 8 \\
\hline EH622305 & 2.42 & Glutathione S-transferase \\
\hline X64399 & 2.41 & Glutathione S-transferase (TAU 19) \\
\hline EB450385 & 2.31 & Glycine-rich RNA binding protein 2 (GRP2) \\
\hline EH617190 & 2.23 & Late embryogenesis abundant protein (Lea5) \\
\hline CV021352 & 2.22 & Senescence associated gene 21 (SAG21) \\
\hline AB020590 & 2.18 & Mitogen associate protein kinase 3 (MPK3) \\
\hline HM466974 & 2.15 & MYC2 transcription factor \\
\hline BP132352 & 2.12 & Alpha-glucan, water dikinase \\
\hline EH616548 & 2.10 & Drought-Responsive Binding factor 2A ( DREB2A) \\
\hline AB063575 & 2.07 & WRKY domain transcription factor \\
\hline DV999707 & 1.99 & Zeaxanthin epoxidase \\
\hline EH623737 & 1.69 & Homeobox transcription factor \\
\hline CV016057 & 1.62 & Stress-responsive protein putative \\
\hline AF112863 & 1.62 & Syntaxin 125 \\
\hline EB439278 & 1.56 & Responsive to ABA 18 ( RAB18) \\
\hline EH617567 & 1.52 & Senescence associated gene 21 \\
\hline FG136072 & 1.44 & Alpha-glucan phosphorylase 2 \\
\hline AF053077 & 1.42 & Zinc-finger protein (zfp) transcription factor \\
\hline & &
\end{tabular}




\begin{tabular}{lll}
\hline TC139820 & 1.40 & Nam-like protein 10 \\
\hline EH615107 & 1.24 & Early responsive to dehydration 15 (ERD15) \\
\hline EB427789 & 1.07 & Aldehyde Dehydrogenase 7B4 ( ALDH7B4) \\
\hline EB431441 & 1.04 & Glutathione transferase \\
\hline
\end{tabular}

\section{DISCUSSION}

Plants are routinely subjected to combinatory abiotic stresses $[9,10]$ and plant treatment with one type of abiotic stress can induce plant resistance to different types of unfavorable conditions $[11,12,16]$. This occurs because of activation in resistance pathway that was not specific to one type of stress, which is known as cross-tolerance to environmental stresses [13]. Cross-tolerance occurs as a result of activation signalling pathways, changes in the level and signalling of hormone, synthesis low molecular weight secondary metabolites, as well as increasing in antioxidant and detoxification activity $[14,15]$.

Over each day and across the season plants are exposed to various light intensities. Plant exposures to high irradiance stress trigger plant responses to other type of stresses because of triggering both local and systemic signals and the innate immune responses against both biotic and abiotic stresses $[16,17,40]$. The leaves of tobacco plants that experienced HL contained lower chlorophyll level in comparison to LL leaves (Figure 1b). This finding was in agreement with studies on other plants [41, 42, 43, 44]. This is because HL stress tends to inhibit chloroplasts biosynthesis and increases its degradation [45]. However, LRCs and $\mathrm{CO}_{2}$ curves were slightly decreased due to HL pre-treatment (Figure 2a, b). In responding to prevailing light availability, leaves can alter their structure and make adjustments in development and metabolism in which result in acclimation of photosynthesis [46]. Plants grow under HL condition can perform high rates of photosynthesis even with less chlorophyll in their leaves in comparison to LL leaves [24]. The higher accumulation of biomass under HL condition (Figure 3a, b) was because of an increase in the number and total area of the leaves $[24,47,48]$. In agreement with previous studies [49, 50], plants grown under LL accumulated less root biomass than HL- grown plants under both water regimes (Figure 5a, b). Detached leaves of HL plants showed less water loss than the LL leaves (Figure 6a). The memory of 7 days of HL treatment, which remains when the plants were returned to LL condition, caused structural leaf modification that was less favorable to water loss [16]. This conclusion is further supported by the data presented in (Table 1) in which HL-grown leaves accumulated transcripts encoding the GLYCINE-RICH RNA BINDING PROTEIN (GRPs) that enhance drought stress tolerance via the stomatal closure in the guard cells [32, 33].

With the exception of the HL-grown and 7 days drought-stressed plants, the leaves contain similar amount of water under all conditions (Figure 6b). The leaves of HL and 7 days drought-stressed plants contain higher amount of water than the LL and 7 days droughtstressed plants (Figure 6b). The memory of excess light that triggered by short term exposure to HL remains for several days in the plant [16]. This "light memory" can elevate production of ROS and activate signalling pathways which improve plant responses to water deficient condition [51, 52]. In addition, the generated ROS in the chloroplast transmitted retrograde signalling to the nucleus [53] and triggered responses pathways that significantly decreased water loss in the leaves of HL treated plants (Figure 6a) and increased the accumulation of transcripts encoding the GLYCINE-RICH RNA BINDING PROTEIN (GRPs) that enhance the stomatal closure (Table 1) [32, 33]. As a result, the HL plants had higher amount of water in their leaves than the LL plants after 7 days of drought treatment (Figure 6b). In addition, water deficient condition results in the increased water uptake and stomatal closure in order to compensate the lost water by transpiration $[5,54,55,56,57]$. Hence, the higher water content in HL and 7 days drought-treated leaves is probably linked to enhanced water uptake (Figure 6c) or/and stomatal closure (Figure 6a). Therefore, it is possible that the higher water content in HL and 7 days drought-treated leaves was due to the interaction between high irradiance and water deficient effects. The survival rate in 21 days drought stressed-plants that re- 
watered for 3 days was $50 \%$ in HL-grown plants, whereas none of LL plants survived after rewatering (Figure $7 \mathrm{a}, \mathrm{b}$ ). This increase in the survival rate of drought-stressed and HL-treated plants is consistent with data presented in (Figure 6a) in which the leaves of plants that had experienced HL had less water loss, more relative water content in the leaves (Figure 6b) and accumulated transcripts encoding the GLYCINE-RICH RNA BINDING PROTEIN (GRPs) that enhance the stomatal closure (Table 1) [32, 33].

The transcript profile of the leaves showed that the abundance of many transcripts related with drought resistance were increased by HL pre-treatment (Table 1). For instance, the transcripts encoding DROUGHT-RESPONSIVE ELEMENT BINDING FACTORS (DREB and DREB2A) were induced due to HL treatment (Table 1). Several genes that modify responses to water deficient condition are activated by DREBs transcription factors [28, 29]. The increased survival rate in HL and drought treated plants, which accumulated DREBs transcripts, is consistent with literature evidence in which transgenic tobacco plants had better survival rate under drought condition via over-expressing of the AhDREBl gene, compared to the wild type plants $[29,30,31,58,59,60]$. Similarly, the transgenic rice plants overexpressing $D R E B 1 A$ and $D R E B 1 B$ showed enhanced drought resistance, fast stomatal closure and less water loss [61, 62]. Furthermore, the abundance of transcripts encoding MYCs transcription factors were induced due to HL treatment (Table 1). The MYCs activate ABAbiosynthesis related genes [63], involve in the regulation of ABA-induced expressed genes under water deficient condition [64], positively regulate oxidative stress tolerance [65], organize the cross-talk during plant exposure to different type of stresses [66] and they are a key regulator in JA synthesis and signalling [36, 67].

The HL-treated leaves accumulated transcripts encoding zeaxanthin epoxidase (ZEP; Table 1). Previous studies concerning the effects of ZEP on plant resistance to water deficient condition have reported that Arabidopsis plants overexpressing the AtZEP gene exhibited more vigorous growth, as well as much higher abundance of stress-related transcripts and smaller stomatal aperture than non-transgenic Arabidopsis plants under water stress condition [68]. Similarly, transgenic tobacco plants accumulated MsZEP via the MsZEP over expression improved plant performance under water stress condition through the regulation in ABA levels and signalling, as well as an activation of various drought related genes [69].

Hence, the better survival rate observed in HL and drought-stressed plants is due to plant acclimation state to high light intensity that alters responses to drought conditions. In addition, plants exposed to high irradiance induce various resistance mechanisms and set of signalling pathways that were not persist in the plants that only had experienced low irradiance.

\section{CONCLUSION}

The data of this study show that short term exposure to high irradiance created a memory of light stress that remains after returning the plant to LL and creates a regulation that made the plants more resistance to water deficient condition. Furthermore, the pre-treatment with HL caused physiological and transcriptomic changes that resulted in the activation of the innate immune defences and improved plant performance under water deficient conditions. Moreover, data are presented showing that cross-tolerance between high light and drought stress activated different stress-related pathways that cross the boundaries of high light and drought stresses.

These findings offer a new understanding about the role of short term exposure to HL on tobacco plant performance under drought conditions. As a future prospect, the new knowledge found in this study should be translated into other crops in order to select the more tolerant varieties to drought stress. 


\section{REFERENCE}

[1] W. Wang, B. Vinocur, and A. Altman, "Plant responses to drought, salinity and extreme temperatures: towards genetic engineering for stress tolerance," (in eng), Planta, vol. 218, no. 1, pp. 1-14, 2003, doi: 10.1007/s00425-003-1105-5.

[2] S. Wani, V. Kumar, V. Shriram, and S. Sah, "Phytohormones and their metabolic engineering for abiotic stress tolerance in crop plants," The Crop Journal, vol. 4, p. 162, 04/01 2016, doi: 10.1016/j.cj.2016.01.010.

[3] Y. Osakabe, K. Osakabe, K. Shinozaki, and L. S. Tran, "Response of plants to water stress," (in eng), Front Plant Sci, vol. 5, p. 86, 2014, doi: 10.3389/fpls.2014.00086.

[4] N. Suzuki, S. Koussevitzky, R. Mittler, and G. Miller, "ROS and redox signalling in the response of plants to abiotic stress," (in eng), Plant Cell Environ, vol. 35, no. 2, pp. 259-70, Feb 2012, doi: 10.1111/j.13653040.2011.02336.x.

[5] D. Golldack, C. Li, H. Mohan, and N. Probst, "Tolerance to drought and salt stress in plants: Unraveling the signaling networks," (in eng), Front Plant Sci, vol. 5, p. 151, 2014, doi: 10.3389/fpls.2014.00151.

[6] M. Hussain et al., "Drought stress in sunflower: Physiological effects and its management through breeding and agronomic alternatives," Agricultural Water Management, vol. 201, pp. 152-166, 03/31 2018, doi: 10.1016/j.agwat.2018.01.028.

[7] D. Bartels and R. Sunkar, "Drought and Salt Tolerance in Plants," Critical Reviews in Plant Sciences, vol. 24, no. 1, pp. 23-58, 2005/02/23 2005, doi: 10.1080/07352680590910410.

[8] J. A. Chowdhury, M. Karim, Q. Khaliq, A. Ahmed, and M. Shawquat, "Effect of drought stress on gas exchange characteristics of four soybean genotypes," Bangladesh Journal of Agricultural Research, vol. 41, p. 195, 06/16 2016, doi: 10.3329/bjar.v41i2.28215.

[9] Y. Jiang and B. Huang, "Drought and Heat Stress Injury to Two Cool-Season Turfgrasses in Relation to Antioxidant Metabolism and Lipid Peroxidation," Crop Science - CROP SCI, vol. 41, 03/01 2001, doi: 10.2135/cropsci2001.412436x.

[10] A. S. Moffat, "Plant genetics. Finding new ways to protect drought-stricken plants," (in eng), Science, vol. 296, no. 5571, pp. 1226-9, May 17 2002, doi: 10.1126/science.296.5571.1226.

[11] G. M. Pastori and C. H. Foyer, "Common components, networks, and pathways of cross-tolerance to stress. The central role of "redox" and abscisic acid-mediated controls," (in eng), Plant Physiol, vol. 129, no. 2, pp. 460-8, Jun 2002, doi: 10.1104/pp.011021.

[12] R. Mittler, "Abiotic stress, the field environment and stress combination," (in eng), Trends Plant Sci, vol. 11, no. 1, pp. 15-9, Jan 2006, doi: 10.1016/j.tplants.2005.11.002.

[13] R. M. Bostock, "Signal crosstalk and induced resistance: straddling the line between cost and benefit," (in eng), Аnnu Rev Phytopathol, vol. 43, pp. 545-80, 2005, doi: 10.1146/annurev.phyto.41.052002.095505.

[14] J. C. Cushman and H. J. Bohnert, "Genomic approaches to plant stress tolerance," (in eng), Curr Opin Plant Biol, vol. 3, no. 2, pp. 117-24, Apr 2000, doi: 10.1016/s1369-5266(99)00052-7.

[15] M. Fujita et al., "Crosstalk between abiotic and biotic stress responses: a current view from the points of convergence in the stress signaling networks," (in eng), Curr Opin Plant Biol, vol. 9, no. 4, pp. 436-42, Aug 2006, doi: 10.1016/j.pbi.2006.05.014.

[16] S. Karpiński, M. Szechyńska-Hebda, W. Wituszyńska, and P. Burdiak, "Light acclimation, retrograde signalling, cell death and immune defences in plants," (in eng), Plant Cell Environ, vol. 36, no. 4, pp. 73644, Apr 2013, doi: 10.1111/pce.12018.

[17] C. H. Foyer and G. Noctor, "Redox regulation in photosynthetic organisms: signaling, acclimation, and practical implications," (in eng), Antioxid Redox Signal, vol. 11, no. 4, pp. 861-905, Apr 2009, doi: 10.1089/ars.2008.2177

[18] S. Karpinski, H. Gabrys, A. Mateo, B. Karpinska, and P. M. Mullineaux, "Light perception in plant disease defence signalling," (in eng), Curr Opin Plant Biol, vol. 6, no. 4, pp. 390-6, Aug 2003, doi: 10.1016/s13695266(03)00061-x.

[19] M. Sierla, M. Rahikainen, J. Salojärvi, J. Kangasjärvi, and S. Kangasjärvi, "Apoplastic and chloroplastic redox signaling networks in plant stress responses," (in eng), Antioxid Redox Signal, vol. 18, no. 16, pp. 2220-39, Jun 12013 , doi: 10.1089/ars.2012.5016.

[20] M. Sierla, C. Waszczak, T. Vahisalu, and J. Kangasjärvi, "Reactive Oxygen Species in the Regulation of Stomatal Movements," (in eng), Plant Physiol, vol. 171, no. 3, pp. 1569-80, Jul 2016, doi: $10.1104 /$ pp.16.00328.

[21] S. Karpinski and M. Szechyńska-Hebda, "Cellular light memory, photo-electrochemical and Redox retrograde signaling in plants," Journal of Biotechnology, Computational Biology and Bionanotechnology, vol. 9.73 , pp. 27-39, 01/01 2012, doi: 10.5114/bta.2012.46566.

[22] P. Mühlenbock et al., "Chloroplast signaling and LESION SIMULATING DISEASE1 regulate crosstalk between light acclimation and immunity in Arabidopsis," (in eng), Plant Cell, vol. 20, no. 9, pp. 2339-56, Sep 2008, doi: 10.1105/tpc.108.059618.

[23] A. Fini et al., "Drought stress has contrasting effects on antioxidant enzymes activity and phenylpropanoid biosynthesis in Fraxinus ornus leaves: an excess light stress affair?," (in eng), J Plant Physiol, vol. 169, no. 10, pp. 929-39, Jul 1 2012, doi: 10.1016/j.jplph.2012.02.014

[24] B. Karpinska et al., "The redox state of the apoplast influences the acclimation of photosynthesis and leaf metabolism to changing irradiance," (in eng), Plant Cell Environ, vol. 41, no. 5, pp. 1083-1097, May 2018, doi: $10.1111 /$ pce. 12960 . 
[25] Lü S, Zhao H, Des Marais DL, et al. Arabidopsis ECERIFERUM9 involvement in cuticle formation and maintenance of plant water status. Plant Physiol. vol.159, no. 3, pp. 930-944. doi:10.1104/pp. 2012. 112.19869

[26] H. Lichtenthaler and C. Buschmann, "Chlorophylls and carotenoids: Measurements and characterization by UV-Vis spectroscopy," Food Analytical Chemistry: Pigments, Colorants, Flavors, Texture and Bioactive Food Components, pp. 171-178, 01/01 2005.

[27] Rasool, Brwa et al. "Catalase, glutathione, and protein phosphatase 2A-dependent organellar redox signalling regulate aphid fecundity under moderate and high irradiance." Plant, cell \& environment vol. 43, no.1, pp. 209-222, 2020 doi: $10.1111 /$ pce. 13669

[28] Q. Liu, N. Zhao, K. Yamaguch-Shinozaki, and K. Shinozaki, "Regulatory role of DREB transcription factors in plant drought, salt and cold tolerance," Chinese Science Bulletin, vol. 45, pp. 970-975, 06/01 2000, doi: 10.1007/BF02884972.

[29] N. Liu et al., "Cloning and functional characterization of PpDBF1 gene encoding a DRE-binding transcription factor from Physcomitrella patens," (in eng), Planta, vol. 226, no. 4, pp. 827-38, Sep 2007, doi: 10.1007/s00425-007-0529-8.

[30] T. H. Hsieh, J. T. Lee, Y. Y. Charng, and M. T. Chan, "Tomato plants ectopically expressing Arabidopsis CBF1 show enhanced resistance to water deficient stress," (in eng), Plant Physiol, vol. 130, no. 2, pp. 61826, Oct 2002, doi: 10.1104/pp.006783.

[31] T. H. Hsieh et al., "Heterology expression of the Arabidopsis C-repeat/dehydration response element binding factor 1 gene confers elevated tolerance to chilling and oxidative stresses in transgenic tomato," (in eng), Plant Physiol, vol. 129, no. 3, pp. 1086-94, Jul 2002, doi: 10.1104/pp.003442.

[32] J. S. Kim et al., "Glycine-rich RNA-binding protein 7 affects abiotic stress responses by regulating stomata opening and closing in Arabidopsis thaliana," (in eng), Plant J, vol. 55, no. 3, pp. 455-66, Aug 2008, doi: 10.1111/j.1365-313X.2008.03518.x.

[33] M. Czolpinska and M. Rurek, "Plant Glycine-Rich Proteins in Stress Response: An Emerging, Still Prospective Story," (in eng), Front Plant Sci, vol. 9, p. 302, 2018, doi: 10.3389/fpls.2018.00302.

[34] X. Wang, B. Du, M. Liu, N. Sun, and X. Qi, "Arabidopsis Transcription Factor WRKY33 Is Involved in Drought by Directly Regulating the Expression of CesA8," American Journal of Plant Sciences, vol. 04, pp. 21-27, 01/01 2013, doi: 10.4236/ajps.2013.46A004.

[35] A. Banerjee and A. Roychoudhury, "WRKY proteins: signaling and regulation of expression during abiotic stress responses," (in eng), ScientificWorldJournal, vol. 2015, p. 807560, 2015, doi: 10.1155/2015/807560.

[36] T. Javed, R. Shabbir, A. Ali, I. Afzal, U. Zaheer, and S. J. Gao, "Transcription Factors in Plant Stress Responses: Challenges and Potential for Sugarcane Improvement," (in eng), Plants (Basel), vol. 9, no. 4, Apr 10 2020, doi: 10.3390/plants9040491.

[37] N. Schwarz et al., "Tissue-specific accumulation and regulation of zeaxanthin epoxidase in Arabidopsis reflect the multiple functions of the enzyme in plastids," (in eng), Plant Cell Physiol, vol. 56, no. 2, pp. 34657, Feb 2015, doi: 10.1093/pcp/pcu167.

[38] M. W. Bianchi, C. Roux, and N. Vartanian, "Drought regulation of GST8, encoding the Arabidopsis homologue of ParC/Nt107 glutathione transferase/peroxidase," (in eng), Physiol Plant, vol. 116, no. 1, pp. 96-105, Sep 2002, doi: 10.1034/j.1399-3054.2002.1160112.x.

[39] J. Xu et al., "Transgenic Arabidopsis Plants Expressing Tomato Glutathione S-Transferase Showed Enhanced Resistance to Salt and Drought Stress," (in eng), PLoS One, vol. 10, no. 9, p. e0136960, 2015, doi: 10.1371/journal.pone.0136960.

[40] M. Szechyńska-Hebda, J. Kruk, M. Górecka, B. Karpińska, and S. Karpiński, "Evidence for light wavelength-specific photoelectrophysiological signaling and memory of excess light episodes in Arabidopsis," (in eng), Plant Cell, vol. 22, no. 7, pp. 2201-18, Jul 2010, doi: 10.1105/tpc.109.069302.

[41] G. Zervoudakis, G. Salachas, Kaspiris, and Konstantopoulou, "Influence of Light Intensity on Growth and Physiological Characteristics of Common Sage (Salvia officinalis L.)," Brazilian Archives of Biology and Technology, vol. 55, pp. 89-95, 02/01 2012, doi: 10.1590/S1516-89132012000100011.

[42] J. F. d. C. Gonçalves, D. C. d. S. Barreto, U. M. d. Santos Junior, A. V. Fernandes, P. d. T. B. Sampaio, and M. S. Buckeridge, "Growth, photosynthesis and stress indicators in young rosewood plants (Aniba rosaeodora Ducke) under different light intensities," Brazilian Journal of Plant Physiology, vol. 17, pp. 325334, 2005. [Online]. Available: http://www.scielo.br/scielo.php?script=sci_arttext\&pid=S167704202005000300007\&nrm=iso.

[43] M. Mielke and B. Schaffer, "Photosynthetic and growth responses of Eugenia uniflora L. seedlings to soil flooding and light intensity," Environmental and Experimental Botany, vol. 68, pp. 113-121, 05/06 2010, doi: 10.1016/j.envexpbot.2009.11.007.

[44] X.-y. Yang, X.-f. Ye, G.-s. Liu, H.-q. Wei, and Y. Wang, "Effects of light intensity on morphological and physiological characteristics of tobacco seedlings," Ying yong sheng tai xue bao = The journal of applied ecology / Zhongguo sheng tai xue xue hui, Zhongguo ke xue yuan Shenyang ying yong sheng tai yan jiu suo zhu ban, vol. 18, pp. 2642-5, 12/01 2007.

[45] Zhang Q, Su LJ, Chen JW, Zeng XQ, Sun BY, Peng CL. The antioxidative role of anthocyanins in Arabidopsis under high-irradiance. Biol. Plantarum. Vol. 56, pp. 97-104

[46] K. Müller et al., "A red light-controlled synthetic gene expression switch for plant systems," (in eng), Mol Biosyst, vol. 10, no. 7, pp. 1679-88, Jul 2014, doi: 10.1039/c3mb70579j.

[47] X.-y. Yao, X. Liu, Z.-g. Xu, and X.-1. Jiao, "Effects of light intensity on leaf microstructure and growth of rape seedlings cultivated under a combination of red and blue LEDs," Journal of Integrative Agriculture, vol. 16, pp. 97-105, 01/31 2017, doi: 10.1016/S2095-3119(16)61393-X. 
[48] D. Fanourakis et al., "Stomatal behavior following mid- or long-term exposure to high relative air humidity: A review," (in eng), Plant Physiol Biochem, vol. 153, pp. 92-105, 2020/08// 2020, doi: 10.1016/j.plaphy.2020.05.024.

[49] H. An and Z. P. Shangguan, "Effects of light intensity and nitrogen application on the growth and photosynthetic characteristics of Trifolium repens L," Shengtai Xuebao/ Acta Ecologica Sinica, vol. 29, pp. 6017-6024, 01/01 2009.

[50] Y. Wang, Q. Guo, and M. Jin, "[Effects of light intensity on growth and photosynthetic characteristics of Chrysanthemum morifolium]," (in chi), Zhongguo Zhong Yao Za Zhi, vol. 34, no. 13, pp. 1632-5, Jul 2009.

[51] R. Mittler, S. Vanderauwera, M. Gollery, and F. Van Breusegem, "Reactive oxygen gene network of plants," (in eng), Trends Plant Sci, vol. 9, no. 10, pp. 490-8, Oct 2004, doi: 10.1016/j.tplants.2004.08.009.

[52] M. A. Torres and J. L. Dangl, "Functions of the respiratory burst oxidase in biotic interactions, abiotic stress and development," (in eng), Curr Opin Plant Biol, vol. 8, no. 4, pp. 397-403, Aug 2005, doi: 10.1016/j.pbi.2005.05.014.

[53] K. J. Dietz, I. Turkan, and A. Krieger-Liszkay, "Redox- and Reactive Oxygen Species-Dependent Signaling into and out of the Photosynthesizing Chloroplast," (in eng), Plant Physiol, vol. 171, no. 3, pp. 1541-50, Jul 2016, doi: 10.1104/pp.16.00375.

[54] H. Yu et al., "Activated expression of an Arabidopsis HD-START protein confers drought tolerance with improved root system and reduced stomatal density," (in eng), Plant Cell, vol. 20, no. 4, pp. 1134-51, Apr 2008, doi: 10.1105/tpc.108.058263.

[55] L. Yu et al., "Arabidopsis enhanced drought tolerance1/HOMEODOMAIN GLABROUS11 confers drought tolerance in transgenic rice without yield penalty," (in eng), Plant Physiol, vol. 162, no. 3, pp. 1378-91, Jul 2013, doi: 10.1104/pp.113.217596.

[56] Z. Zhu et al., "Overexpression of AtEDT1/HDG11 in Chinese Kale (Brassica oleracea var. alboglabra) Enhances Drought and Osmotic Stress Tolerance," (in eng), Front Plant Sci, vol. 7, p. 1285, 2016, doi: 10.3389/fpls.2016.01285

[57] M. Chaves, J. Flexas, and C. Pinheiro, "Photosynthesis Under Drought and Salt Stress: Regulation Mechanisms From Whole Plant to Cell," Annals of botany, vol. 103, pp. 551-60, 08/01 2008, doi: 10.1093/aob/mcn125

[58] Y. G. Shen, W. K. Zhang, S. J. He, J. S. Zhang, Q. Liu, and S. Y. Chen, "An EREBP/AP2-type protein in Triticum aestivum was a DRE-binding transcription factor induced by cold, dehydration and ABA stress," (in eng), Theor Appl Genet, vol. 106, no. 5, pp. 923-30, Mar 2003, doi: 10.1007/s00122-002-1131-X.

[59] Y. Wang et al., "Drought tolerance evaluation of tobacco plants transformed with different set of genes under laboratory and field conditions," Science Bulletin, vol. 60, pp. 616-628, 03/01 2015, doi: 10.1007/s11434015-0748-5.

[60] R. F. Ahmed, M. Irfan, H. A. Shakir, M. Khan, and L. Chen, "Engineering drought tolerance in plants by modification of transcription and signalling factors," Biotechnology \& Biotechnological Equipment, vol. 34 no. 1, pp. 781-789, 2020/01/01 2020, doi: 10.1080/13102818.2020.1805359.

[61] K. Datta, N. Baisakh, M. Ganguly, S. Krishnan, K. Yamaguchi Shinozaki, and S. K. Datta, "Overexpression of Arabidopsis and rice stress genes' inducible transcription factor confers drought and salinity tolerance to rice," (in eng), Plant Biotechnol J, vol. 10, no. 5, pp. 579-86, Jun 2012, doi: 10.1111/j.14677652.2012.00688.x.

[62] P. Bhatnagar-Mathur et al., "Transgenic peanut overexpressing the DREB1A transcription factor has higher yields under drought stress," Molecular Breeding, 09/19 2013, doi: 10.1007/s11032-013-9952-7.

[63] R. S. Wang et al., "Common and unique elements of the ABA-regulated transcriptome of Arabidopsis guard cells," (in eng), BMC Genomics, vol. 12, p. 216, May 9 2011, doi: 10.1186/1471-2164-12-216.

[64] D. Singh and A. Laxmi, "Transcriptional regulation of drought response: a tortuous network of transcriptional factors," (in eng), Front Plant Sci, vol. 6, p. 895, 2015, doi: 10.3389/fpls.2015.00895.

[65] Y. Yoon, D. Seo, H. Shin, H. Kim, C. Kim, and G. Jang, "The Role of Stress-Responsive Transcription Factors in Modulating Abiotic Stress Tolerance in Plants," Agronomy, vol. 10, p. 788, 06/01 2020, doi: 10.3390/agronomy10060788

[66] K. Shinozaki and K. Yamaguchi-Shinozaki, "Gene networks involved in drought stress response and tolerance," (in eng), J Exp Bot, vol. 58, no. 2, pp. 221-7, 2007, doi: 10.1093/jxb/erl164

[67] M. Boter, O. Ruíz-Rivero, A. Abdeen, and S. Prat, "Conserved MYC transcription factors play a key role in jasmonate signaling both in tomato and Arabidopsis," (in eng), Genes Dev, vol. 18, no. 13, pp. 1577-91, Jul 1 2004, doi: 10.1101/gad.297704.

[68] H. Y. Park et al., "Overexpression of Arabidopsis ZEP enhances tolerance to osmotic stress," (in eng), Biochem Biophys Res Commun, vol. 375, no. 1, pp. 80-5, Oct 10 2008, doi: 10.1016/j.bbrc.2008.07.128.

[69] Z. Zhang et al., "MsZEP, a novel zeaxanthin epoxidase gene from alfalfa (Medicago sativa), confers drought and salt tolerance in transgenic tobacco," (in eng), Plant Cell Rep, vol. 35, no. 2, pp. 439-53, Feb 2016, doi $10.1007 / \mathrm{s} 00299-015-1895-5$ 